A

unc-46

\section{in Cel}

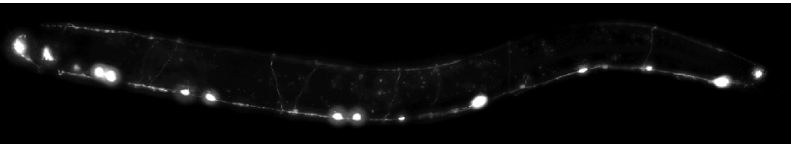

in $\mathrm{Cbr}$

$\because$

B

unc-25



in $\mathrm{Cbr}$

C

gpa-5

\section{in Cel}

?

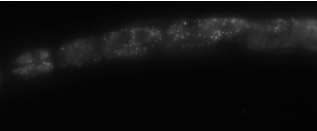

an

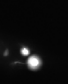

in $\mathrm{Cbr}$

D

oig-1

in Cel

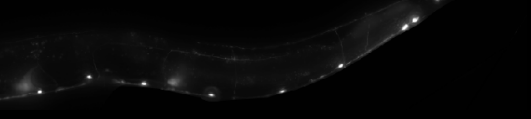

in Cbr

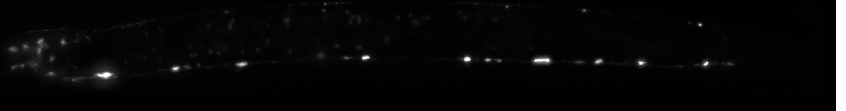

\section{RMEs AVL SIADs RIS D-type DVB Lat. PDB \\ (median) gang.}

$\begin{array}{lllllll}100 \% & 88 \% & 96 \% & 90 \% & 18 & 86 \% & 34 \%\end{array}$

$97 \% \quad 75 \% \quad 96 \% \quad 28 \% \quad 18.5 \quad 85 \%$

$72 \%$

$\begin{array}{ccccc}\text { RMEs } & \text { AVL } & \text { RIS } & \begin{array}{c}\text { D-type } \\ \text { (median) }\end{array} & \text { SIADs } \\ 100 \% & & 16 & 52 \% \\ 100 \% & \begin{array}{c}12 \% \\ \text { (weak) }\end{array} & \begin{array}{c}41 \% \\ \text { (weak) }\end{array} & 15 & 100 \%\end{array}$

$\begin{array}{lllllll}\text { AWAs } & \text { MCs } & \text { M4 } & \text { M1 } & \text { DVB } & \text { PVNs } & \text { PHCs }\end{array}$

$\begin{array}{cccccc}45 \% & & & \end{array}$

$\begin{array}{lllll}47 \% & 89 \% & 21 \% & 79 \% & 66 \%\end{array}$

(weak) (weak) (weak) (weak) (weak)

$95 \%$

(weak)

\title{
Figure S2
}

$\begin{array}{cccccc}\begin{array}{c}\text { Head } \\ \text { neurons }\end{array} & \begin{array}{c}\text { D-type } \\ \text { (median) }\end{array} & \text { DVB } & \text { PVCs } & \text { HSNs } & \text { PDEs } \\ 100 \% & 14 & 72 \% & 100 \% & 36 \% & \\ 100 \% & 17 & & \begin{array}{c}63 \% \\ (\text { weak) }\end{array} & 29 \%\end{array}$

